\title{
Elucidating the Impact of Feeding Behaviour on Body Composition in Finishing Pigs Fed Ad Libitum Using an Integrative Feeding Behaviour Index
}

Hector Hernando Salgado ( $\square$ hector.salgadoromero@canada.ca )

Agriculture and Agri-Food Canada https://orcid.org/0000-0003-0353-2718

Steve Méthot

Agriculture and Agri-Food Canada

Aline Remus

Agriculture and Agri-Food Canada

Marie-Pierre Létourneau-Montminy

Laval University: Universite Laval

Candido Pomar

Agriculture and Agri-Food Canada

Research

Keywords: feeding patterns, individual variation, nutrition, body composition, swine

Posted Date: April 27th, 2021

DOl: https://doi.org/10.21203/rs.3.rs-445190/v1

License: (9) This work is licensed under a Creative Commons Attribution 4.0 International License.

Read Full License 


\section{Abstract}

Background: Large variability in body composition is observed in pigs fed and raised in similar conditions. Part of this variation might be explained by the feeding behavior of pigs, given its effect on metabolic hormones associated with energy regulation and protein metabolism. The objective of this study was to elucidate this relationship by examining body composition with a new index describing feeding behavior in finishing pigs. Feeding behavior and body composition information on 138 pigs during the last $28 \mathrm{~d}$ of the growing phase from three trials were used. For each pig, the sum of the areas between the observed relative cumulative feed intake and the regression line for the evolution of relative feed intake over time was used to calculate the new feeding behavior index. This index quantifies the irregularity of feed intake (IIFI) by integrating different components of feeding behavior into a single measurement. Body lipids and protein composition were estimated by dual X-ray densitometry at the beginning (day 1 ) and end of the finishing phase (day 28 ).

Results: Weak to moderate correlations $(r= \pm 0.31$ to $\pm 0.44 ; P<0.05)$ of IIFI with body composition and performance variables were found only in datasets 1 and 2. However, in dataset 2, IIFI was also correlated with daily feed intake $(r=-0.54 ; P<0.001)$. Irregular feeding behavior is associated to increased proportion of protein (PdDG) and decreased proportion of lipids (LdDG) in body gain. However, IIFI only accounted for $8 \%$ to $14 \%$ and $10 \%$ to $12 \%$ of the total variation of PdDG and LdDG in datasets 2 and 1 , respectively. Additionally, factor analysis showed that the number of meals and IIFI had high loadings in a factor separate from factors associated with body composition or performance, suggesting that body composition and performance are independent of feeding behavior.

Conclusion: Factors other than feeding behavior might be involved in modulating body composition of finishing pigs fed ad libitum.

\section{Background}

A large variation in lipid and protein body composition is observed in pigs fed and raised under similar conditions. Producers need to focus on reducing this variation in order to reach premium grid qualifications in many countries (1). Part of this variation may be associated with differences in feeding behaviour among pigs (2). Feeding behaviour is described in terms of the time course of feed intake, often on a short-term basis, by using parameters such as meal frequency, meal size, and meal duration (3). Feeding behaviour has been found to affect feed efficiency, body composition, and blood concentrations of hormones related to energy regulation (4-6). The number of meals per day and the feed intake rate are the parameters most closely associated with growth performance, while meal size was found to be negatively correlated with feed efficiency (7).

However, inconsistencies have been found in trials studying the influence of feeding behaviour patterns on growth performance and body composition. These inconsistencies can be attributed in part to the large intra-animal variation of conventional parameters used to describe feeding behaviour over time (8). 
Developing better knowledge of the feeding behaviour of pigs using methodologies that account for intraanimal variation and that integrate the various components of this behaviour could help to clarify its impact on body composition.

The index of irregularity of feed intake (IIFI) is a method for describing the feeding behaviour of pigs which can overcome important limitations of conventional parameters (9). This new index is calculated based on the distribution of cumulative feed intake and takes into consideration the intra-animal variability of feeding behaviour over time, usually several consecutive days. The IIFI integrates in a single parameter information on the number, size, and duration of meals, and their distribution over time. This results in a suitable approach for describing individual feeding behaviour in order to better assess its impact on animal performance or health status. The objective of this study was to clarify the effect of individual feeding behaviours as described by the IIFI on the observed variation in body composition in finishing pigs fed ad libitum.

\section{Material And Methods}

\section{Dataset description}

The dataset used for this analysis is described in Salgado et al. (2021), Briefly, real-time feed intake and growth performance information during the 28-d finishing phase of 138 finishing pigs fed ad libitum of 3 datasets was used (10-12) for datasets 1, 2 and 3, respectively. At the beginning of the finishing phase, the pigs weighed $104.9 \pm 7.1 \mathrm{~kg}, 88.3 \pm 5.3 \mathrm{~kg}$, and $83.1 \pm 4.9 \mathrm{~kg}$ on average in trials 1,2 and 3 , respectively, and were allocated to pens with a space allowance of $96 \mathrm{~m}^{2}$. Pigs were of the same highperformance genotype (Fertilis $25 \times$ G performer 8.0; Geneticporc Inc., Saint-Bernard, QC, Canada). The temperature of the room changed from $22^{\circ} \mathrm{C}$ to $18^{\circ} \mathrm{C}$ between the start and end of the trials. Fluorescent lighting controlled by a timer switch was provided from 06:00 to 18:00. Feed was provided and feed intake (FI) was recorded individually using five automated feeding stations (Automatic and Intelligent Precision Feeder; University of Lleida, Lleida, Spain) installed side-by-side in front of the pen. A description of the feeders is available in previous publications $(10,13)$. Pigs were fitted with an electronic ear tag (passive radio frequency identification; Allflex, Saint-Hyacinthe, QC, Canada) that gave them access to the feeding stations.

Detailed information on the treatments and objectives of the experiments is presented in supplementary material in Salgado et al. (9). Briefly, in dataset 1, the performance of pigs fed in a conventional 3-phase group feeding system (3P), a daily-multiphase group feeding system (MPG), and an individual precision feeding system were compared (MPI). In dataset 2, a conventional 3-phase group feeding system was compared to an individual precision feeding system providing different levels of dietary lysine :110\% (MPI 110), $100 \%$ (MPI 100), 90\% (MPI 90), or 80\% (MPI 80) of the estimated Lys requirements. In dataset 3, five dietary treatments varying the amount and type of fibre provided to the pigs were compared. 


\section{Performance and body composition}

In trials 1 and 2, pigs were weighed individually on conventional scales at arrival, twice during the preexperimental phase, and weekly during the study. Total body lean content was measured by dual-energy X-ray absorptiometry (DXA) on days $0,28,56$, and 84 using a densitometry device (GE Lunar Prodigy Advance; GE Healthcare, Madison, WI). Pigs were scanned in the prone position using the total body scanning mode (GE Lunar enCORE, version 8.10.027; GE Healthcare). Anesthesia was induced with sevoflurane (5\%) and maintained with isoflurane (4\%) during the scans. The DXA body lean mass value was converted to its protein chemical equivalent, using the approach proposed by Pomar and Rivest (14). In trial 3, pigs were scanned by DXA following the same procedure as in trials 1 and 2 on days 0 and 28 of the feeding phase of interest (finishing phase).

\section{Data compilation and calculations}

Feeding and body composition data collected from the last 28 days were used in the present study. However, the feeding behaviour data of the fourth week of each trial was removed because of the possible alteration of the normal feeding behaviour of the pigs due to changes in group size during that week. The reduction in group size is the consequence of removing pigs completing the $28 \mathrm{~d}$ of the feeding phase. A previous analysis of the data showed that changes in lipid mass and variability in body composition between pigs were considerably larger in this phase compared with preceding feeding phases. Therefore, only data from the finishing-phase was used in this study.

Data were imported into SAS (version 9.4; SAS Institute Inc., Cary, NC) for selection, cleaning, processing, and analysis. Errors in the data such as visits to feeders without intake were also removed. Feeder visits by the same pig at intervals less than 2 min apart were combined into one meal. The main details for meal criteria and cleaning methods of the data are given in Salgado et al. (2021).

The average daily feed intake (ADFI, $g / d)$, average daily gain (ADG, $g / d$ ), average daily protein deposition (PD; $g / d)$, and average daily lipid deposition (LD; $g / d$ ) were calculated by dividing the corresponding variables by the duration of the period $(28 \mathrm{~d})$. The proportion of protein (PdDG) and the proportion of lipids (LdDG) of body weight gain were calculated by dividing LD or PD by ADG and expressed as percentages.

Index of irregularity of feed intake

A detailed description of the calculation of the index is provided in Salgado et al. (9). Briefly, for each week and each pig, a monotonically increasing step function using relative cumulative $\mathrm{Fl}$ and relative time over a week was obtained. A linear regression model was then fitted between weekly relative cumulative $\mathrm{FI}$ and relative time for each pig. This regression line represents a hypothetical situation in which a pig would continually eat the same amount of feed over the week (Figure 1). The areas between the step function and the regression line were summed to obtain the weekly IIFI for each pig (9). Although, 
a polynomial model was also significant, the linear model was chosen as the linear effect itself explained more than $97 \%$ of the total observed variation while the quadratic term only increased the explained variation by $0.02 \%$. The final IIFI for each pig is the average of the weekly indexes obtained during the first 3 weeks of the last feeding phase of each trial. Pigs with high IIFI values have less regular feeding behaviour patterns than pigs with low values.

In addition to IIFI, the number of meals, FI per meal (g), meal duration (min), the interval between meals ( $\mathrm{min}$ ) and FI rate $(\mathrm{g} / \mathrm{min}$ ) were calculated on a daily basis for each pig during the study period. The feed intake rate was calculated by dividing the feed intake of each meal by the duration of the meal. These daily values were further averaged over a one-week period and the 3-week averages were used to compare the relationship of IIFI and conventional parameters with performance and body composition.

\section{Statistical analysis}

All analyses were performed separately within each dataset. To determine the relationship between feeding behaviour and body composition and performance, Spearman's correlations were obtained between IIFI and $A D F I, A D G$, feed-to-gain ratio $(F: G), L d D G$, and PdDG. For datasets in which IIFI was correlated with body composition variables (LdDG and PdDG), a mixed model for those variables was used with IIFI as the independent variable and treatment and the interaction treatment $\times$ IIFI as fixed factors. Since this interaction was never significant, it was not included in the final model. The pig was considered to be the experimental unit. Type III sum of squares was used to quantify the contribution of feeding behaviour to the total explained variance of the composition of body gain.

To identify the factors that explain the variables related to feeding behaviour, growth performance, body composition, and nutrient balance, an explanatory factor analysis was performed within each dataset using the factor analysis procedure in the Minitab statistical package (version 19; Minitab Inc., State College, PA). Variables that were known a priori to share variance (e.g., ADG, BW and F:G) were not included in the analysis. Growth performance (BW, F:G, Lys, and protein intake), growth composition (LD and PD), and nutrient balance ( $\mathrm{N}$ retention and $\mathrm{N}$ excretion) variables were averaged over the last feeding phase (28 d), and plasma composition (protein and urea in plasma, only in dataset 2) was measured on the last day of the experiment. Only variables with a loading factor of at least 0.7 were used for interpretation. Factors with eigenvalues greater than 1.0 were extracted. The quartimax normalized rotational strategy was applied to simplify the rows of the factor loading matrix.

\section{Results And Discussion}

Pigs consumed feed and gained weight according to the expected performance of the genotype throughout the three trials that generated the data used in the present study (Table 1). For the current analysis, only data from the finishing phase were used for the reasons mentioned in the Material and Method section. Detailed information on growth performance, body composition, and feeding programs was reported previously (10-12). Briefly, CP intake was reduced by $10 \%$ with a multiphase-group feeding program and by $11 \%$ with multiphase-individual feeding (10) in the finishing phase. Feeding pigs daily 
tailored diets containing $110 \%, 100 \%$ or $90 \%$ of the estimated lysine requirements resulted in a significant reduction of CP and Lys intake $(P<0.01)$ in the finishing phase, specifically from $331 \mathrm{~g} / \mathrm{d}$ to $290 \mathrm{~g} / \mathrm{d}$ for $\mathrm{CP}$, and from $18.1 \mathrm{~g} / \mathrm{d}$ to $12.4 \mathrm{~g} / \mathrm{d}$ for Lys $(11)$. In both studies $(10,11)$, dietary treatments did not affect growth performance and body composition, except for the commercial treatment in (10), which decreased ADFI $(P<0.05)$ and body lipid content $(P<0.05)$, and the multiphase treatment containing $80 \%$ of the estimated lysine requirements in $(11)$, which reduced body protein mass $(P<0.01)$. Thus, data from those treatments were removed from the current analysis. In dataset 3 , the diets with high dietary fibre decreased $\operatorname{ADFI}(P<0.01)$ without effects on growth performance and body composition (12).

Table 1 Descriptive statistics for performance, body composition, nutrient balance and feeding behaviour of finishing pigs in the last feeding phase, for datasets 1,2 and 3.

\begin{tabular}{|c|c|c|c|c|c|c|}
\hline & \multicolumn{2}{|c|}{ Study $1(n=37)$} & \multicolumn{2}{|c|}{ Study $2(n=46)$} & \multicolumn{2}{|c|}{ Study $3(n=55)$} \\
\hline & Mean & SD & Mean & SD & Mean & SD \\
\hline \multicolumn{7}{|l|}{ Growth performance } \\
\hline Initial BW (kg) & 106.1 & 6.6 & 88.4 & 4.6 & 83.1 & 4.9 \\
\hline Final BW (kg) & 135.3 & 8.3 & 116.8 & 8.2 & 116.7 & 6.7 \\
\hline Average daily gain (kg) & 1.0 & 0.1 & 1.0 & 0.2 & 1.2 & 0.2 \\
\hline Average daily feed intake $(\mathrm{kg})$ & 3.4 & 0.3 & 2.9 & 0.5 & 3.2 & 0.4 \\
\hline Feed-to-gain ratio $(\mathrm{kg} / \mathrm{kg})$ & 3.3 & 0.3 & 2.9 & 0.5 & 2.6 & 0.4 \\
\hline \multicolumn{7}{|l|}{ Body composition } \\
\hline Protein retention (g/d) & 118.1 & 21.8 & 136.5 & 23.5 & 160.3 & 20.6 \\
\hline Lipid retention $(\mathrm{g} / \mathrm{d})$ & 475.4 & 63.3 & 363.8 & 99.3 & 403.2 & 60.4 \\
\hline Protein gain (\% ADG) & 11.2 & 1.2 & 13.6 & 1.2 & 13.5 & 1.1 \\
\hline Lipids gain (\% ADG) & 45.0 & 5.5 & 35.6 & 5.5 & 34.3 & 4.8 \\
\hline \multicolumn{7}{|l|}{ Nitrogen balance } \\
\hline Nitrogen retention (g/pig) & 526.5 & 96.6 & 611.4 & 105.1 & 718.0 & 92.3 \\
\hline Nitrogen excretion (g/pig) & 1445.7 & 204.3 & 779.4 & 205.7 & 1616.0 & 301.7 \\
\hline \multicolumn{7}{|l|}{ Feeding behavior } \\
\hline Index of irregularity of feed intake ${ }^{1}$ & 187.9 & 25.0 & 206.7 & 31.3 & 184.3 & 45.6 \\
\hline Number of daily meals & 7.0 & 1.7 & 7.3 & 1.5 & 7.2 & 1.8 \\
\hline
\end{tabular}


${ }^{1}$ Calculated by summing the absolute values of the areas of the deviation between the regression line of the relative cumulative feed intake over a week and the step function of the observed cumulative feed intake. The regression line represents the hypothetical situation of a pig that eats the same amount of feed continuously over a week.

The health problems observed during the studies consist of one rectal prolapse in trial 1, three cases of severe lameness in trial 2, and four pigs with either severe lameness, anorexia, or sudden death in trial 3. These health disorders were unrelated to the treatments, and data from all these animals were removed from the analysis.

\section{Relationship between feeding patterns and growth performance and body composition}

Correlations among ADG, PD and LD indicate that, both PD $(r=0.77)$ and $L D(r=0.46)$ increase as ADG increases. However, the variation in body composition observed on this study indicates that some pigs are more efficient in the use of energy for PD resulting in less energy available for LD, which outcomes in differences of LD among pigs. Thus, in the current study, the composition of the gain was broken down into proportions of protein and lipids, referred to as PdDG and LdDG, respectively. Pigs with leaner gain have increased PD and decreased LD ( $r=0.83$ and $r=-0.62$ for PD and LD vs PdDG, respectively) compared with pigs having higher LdPD. The direction of those correlations were consistent across datasets.

Correlations of the feeding behaviour described with IIFI and body composition were significant but moderate in datasets 1 and 2 (Table 2). The dimention of these correlations were consistent with previous studies reporting correlations of body composition with feeding behaviour but described with conventional parameters $(2,15-18)$. However, those reported associations are also weak $(r= \pm 0.20$ to \pm 0.40 ) and not consistent between studies. For example, Carcò et al. (2) reported a negative correlation between meal duration and lipid retention rate whereas other studies found a positive correlation $(15,16)$. No correlation was found between feed intake per meal and fatness in some studies (15), while others found an increase in fatness due to greater feed intake per meal $(2,17,18)$. Carcò et al. $(2)$ reported that ad libitum pigs with a high feed intake rate $(52-119 \mathrm{~g} / \mathrm{min})$ had a greater proportion of fat in the carcass $(14 \%)$ and a $4 \%$ decrease in the proportion of carcass lean cuts. However, on that study feed intake rate was positively correlated with feed intake $(r=0.51 ; P<0.001)$, indicating that pigs with high feed intake rate also had higher feed intake, thus, the influence of feeding behaviour in fatness might be confounded with differences on feed intake.

Table 2 Spearman's correlations for the index of irregularity of feed intake (IIFI) with growth performance and the body gain composition of finishing pigs in datasets 1, 2 and 3 . 


\begin{tabular}{|llll|}
\hline & \multicolumn{3}{c|}{ Index of irregularity of feed intake ${ }^{1}$} \\
\hline Parameter & Dataset 1 & Dataset 2 & Dataset 3 \\
\hline Average daily feed intake $(\mathrm{g} / \mathrm{d})$ & -0.01 & $-0.54^{\star \star \star}$ & $-0.59^{\star \star \star}$ \\
\hline Average daily gain $(\mathrm{g} / \mathrm{d})$ & 0.20 & -0.20 & -0.22 \\
\hline Feed-to-gain ratio $(\mathrm{kg} / \mathrm{kg})$ & -0.28 & $-0.44^{\star *}$ & $-0.40^{\star *}$ \\
\hline Protein deposition in body gain $(\%)$ & $0.36^{*}$ & $0.31^{*}$ & 0.17 \\
\hline Lipid deposition in body gain $(\%)$ & $-0.37^{\star}$ & $-0.32^{\star}$ & -0.11 \\
\hline
\end{tabular}

${ }^{1}$ Calculated by summing the absolute values of the areas of the deviations between the regression line of the relative cumulative feed intake over a week and the step function of the observed cumulative feed intake. The regression line represents the hypothetical situation of a pig that eats the same amount of feed continuously over a week.

$\star$, **, and ${ }^{\star \star *}$ stand for $P<0.05, P<0.01$ and $P<0.001$, respectively.

In the current study, relationships of conventional feeding behaviour parameters with growth performance and body composition were also moderate but inconsistent between datasets 1 and 2 (supplementary material), different to IIFI which had more consistent correlations between datasets. For example, the number of meals had a positive correlation with ADG $(r=0.37 ; P<0.01)$ and LdDG $(r=0.37 ; P<0.01)$, but these correlations were not significant in dataset $2(P>0.05)$; a longer duration of meals was associated with increased LdDG $(r=-0.28 ; P<0.05)$, however, this correlation was positive in dataset $2(r$ $=0.33 ; P<0.05)$. The inconsistencies found in the literature and between datasets of the current study are difficult to explain. Differences in meal criteria between studies (19) and the large intra-animal variability of these behavior parameters might explain inconsistencies in the literature, and inconsistencies between datasets might be the result of the large variation of these conventional parameters across days for a given animal as the same meal criteria was used in each dataset. As demonstrate in Salgado et al. (9) the use of the proposed IIFI removes these important sources of variation (intra-animal and across studies) which is supported by the lower intra-animal CV compared to other conventional parameters ( $\mathrm{CV}=14.9 \%$ vs $37.9 \%$ for IIFI and number of meals, respectively).

In addition, the significant correlations of these conventional parameters with body composition in dataset 1 indicate that leaner gain is associated with few number of meals $(r=-0.38 ; P<0.01)$, of long duration $(r=0.29 ; P<0.05)$. The same information is given by IIFI but using only one single parameter as IIFI integrates different components of the feeding behaviour $(P<0.001)$, such as the number $(r=0.42)$ the duration $(r=0.40)$, size $(r=0.41)$ and distribution $(r=0.4)$ of meals over time (9). All this together makes IIFI a better parameter for studying feeding behavior and its relationship with body composition. Correlations of IIFI with body composition parameters indicate that as IIFI increases (fewer numbers of big meals with long duration), PdDG also increases $(P<0.05)$. Correlations were somewhat weak $(r=$ 
\pm 0.31 to \pm 0.37 ) and only significant in datasets 1 and 2 . Also, the negative correlation of IIFI with ADFI ( $r$ $=-0.54 ; P<0.001)$ in dataset 2 indicates that, in that specific case, body composition was more likely affected by the increase in feed intake of pigs that had more frequent meals than by the feeding behavior itself. Colpoys et al. (16) observed correlations between time spent eating and ADFI, PD and LD. In their study, behavioral parameters were not adjusted to equalize feed intake, and therefore, pigs with high fat deposition were also those with higher feed intake and longer duration of meals. Additionally, those authors pointed out that differences in fat and protein deposition between gilts with free access to feeders vs. gilts fed twice a day were partly explained by ADFI. In that study, ADFI was strongly correlated with PD $(r=0.73 ; P<0.01)$ and LD $(r=0.83 ; P<0.01)$. Feed intake increases fat deposition in part because in growing pigs dietary energy is first partitioned towards maintenance needs and then lean deposition, with the remaining energy used for fat deposition (20).

The index of irregularity of feed intake showed a positive linear relationship with $\operatorname{PdDG}(P<0.05$; Figure 2) but a negative relationship with $\operatorname{LdGD}(P<0.05)$ in datasets 1 and 2 . Although this relationship was significant, it only accounted for $14 \%$ and $12 \%$ of the observed variance in PdDG and LdDG, respectively, in dataset 1 , and $8 \%$ and $10 \%$ of the observed variance in PdDG and LdDG, respectively, in dataset 2 . The interaction treatment $\times$ IIFI was never significant, indicating that the relationship of IIFI with the composition of the gain was similar within treatments. In dataset 2 , the relationship of IIFI with the composition of the gain might depend more on the negative association of IIFI with ADFI than on IIFI itself.

The factor analysis performed in the current analysis showed that IIFI and number of meals did not have strong loadings in factors where loadings for variables associated with body composition were strong, indicating that feeding behaviour variables are fairly independent of body composition variables (Tables 3 to 5). This can be explained by the low contribution of IIFI in the composition of the body gain in dataset 1 , the confounding effect of $\mathrm{FI}$ in the relationship IIFI and body composition in dataset 2 , and, the lack of association of body composition with feeding behavior found in dataset 3 . These results demonstrate that feeding behavior is not an important factor modulating body composition in finishing pigs fed ad libitum. Previous studies have shown no effect of meal frequency on PD, ADG, or Lys oxidation when pigs fed 3 meals per day were compared with pigs fed 8 times per day using isotopic tracers (21), and Remus et al. (22), found no correlation of feeding behaviour with growth performance, $L D$ and $P D$ in growing and finishing pigs fed ad libitum under precision feeding systems.

Table 3 Exploratory factor analysis ${ }^{1}$ (quartimax rotation) with correlation coefficients for growth performance, body composition, feeding behaviour and nutrient balance of finishing pigs in dataset 1 . 


\begin{tabular}{|c|c|c|c|c|c|}
\hline \multirow[t]{2}{*}{ Variable } & Factor1 & Factor2 & Factor3 & Factor4 & \multirow[t]{2}{*}{ Communality } \\
\hline & $\begin{array}{l}\text { Nutrient } \\
\text { Intake }\end{array}$ & $\begin{array}{l}\text { Protein } \\
\text { deposition }\end{array}$ & Growth & $\begin{array}{l}\text { Feeding } \\
\text { behavior }\end{array}$ & \\
\hline Number of daily meals & -0.10 & 0.22 & -0.17 & -0.88 & 0.86 \\
\hline Index of irregularity of feed intake ${ }^{2}$ & 0.09 & -0.28 & -0.30 & 0.77 & 0.77 \\
\hline Body weight (kg) & 0.27 & -0.11 & 0.88 & 0.03 & 0.87 \\
\hline Feed-to-gain ratio & 0.25 & 0.84 & 0.14 & -0.08 & 0.80 \\
\hline Protein deposition (g/d) & 0.24 & -0.93 & 0.05 & 0.18 & 0.96 \\
\hline Lipid deposition (g/d) & 0.32 & 0.16 & 0.72 & -0.09 & 0.65 \\
\hline $\mathrm{N}$ retention (g/pig) & 0.25 & -0.93 & 0.05 & 0.18 & 0.96 \\
\hline N excretion (g/pig) & 0.92 & 0.24 & 0.29 & 0.02 & 0.99 \\
\hline CP intake $(g / d)$ & 0.93 & -0.22 & 0.26 & 0.08 & 0.99 \\
\hline Lys intake (g/d) & 0.95 & -0.23 & 0.03 & 0.09 & 0.96 \\
\hline Variance $^{3}$ & 2.99 & 2.77 & 1.59 & 1.46 & 8.81 \\
\hline Proportion 4 & 0.30 & 0.28 & 0.16 & 0.15 & 0.89 \\
\hline
\end{tabular}

${ }^{1}$ Loadings were assumed to be significant above 0.7 .

${ }^{2}$ Calculated by summing the absolute values of the areas of the deviations between the regression line of the relative cumulative feed intake over a week and the step function of the observed cumulative feed intake. The regression line represents the hypothetical situation of a pig that eats the same amount of feed continuously over a week.

${ }^{3}$ Variability (eigenvalue) in data explained by each factor.

${ }^{4}$ Proportion of the total observed variation in data explained by each factor.

\section{Imposed meal frequency, natural feeding behavior, and metabolic responses}

The linear increase in PdDG and the linear decrease in LdDG as implied by the IIFI increase suggests that irregular feeding behavior, which is associated with fewer and bigger meals, stimulates the proportion of protein in body gain and lessens the proportion of lipids. Growing pigs fed twice daily had higher weight of the flanks and a greater proportion of muscle compared with pigs fed 12-meal daily or ad libitum $(4,5)$. 
This suggests that feeding pigs twice a day may increase utilization of amino acid (AA) for protein synthesis, or may reduce the mobilization from protein and AA catabolism, or both. The increase in AA utilization for protein synthesis in those pigs might be explained by the higher concentrations of insulin, which is an important stimulator of protein synthesis. In fact, the high activity of the insulin-signaling pathway contributes to the increased response of muscle protein synthesis in neonatal pigs (23). In addition, similar studies (24) have reported that the 2-meal regime altered proteins that are involved in protein and amino acid metabolism by down-regulating proteins that catalyze amino acid degradation, such as protein-tyrosine sulfotransferase 1 and proteasome subunit beta type. On the other hand, low meal frequency was associated with decreased perinatal fat weight and inflammatory response in pigs (Initial BW $61.7 \pm 0.7 \mathrm{~kg}$ and final BW $113.6 \pm 1.1 \mathrm{~kg}$ ) fed high-fat diets, and decreased fatty acid uptake (25).

Table 4 Exploratory factor analysis ${ }^{1}$ (quartimax rotation) with correlation coefficients for growth performance, body composition, feeding behaviour, nutrient balance and plasma response of finishing pigs in dataset 2 .

\begin{tabular}{|c|c|c|c|c|}
\hline \multirow[t]{2}{*}{ Variable } & Factor1 & Factor2 & Factor3 & \multirow[t]{2}{*}{ Communality } \\
\hline & CP intake & $\begin{array}{l}\text { Protein } \\
\text { deposition }\end{array}$ & $\begin{array}{l}\text { Feeding } \\
\text { behavior }\end{array}$ & \\
\hline Number of daily meals & -0.22 & -0.16 & -0.79 & 0.69 \\
\hline Index of irregularity of feed intake ${ }^{2}$ & -0.06 & -0.12 & 0.77 & 0.61 \\
\hline Feed-to-gain ratio & -0.09 & 0.84 & 0.36 & 0.84 \\
\hline Body weight (kg) & 0.64 & -0.38 & 0.28 & 0.63 \\
\hline Protein deposition $(\mathrm{g} / \mathrm{d})$ & 0.41 & -0.86 & 0.17 & 0.94 \\
\hline Lipid deposition (g/d) & 0.73 & -0.20 & 0.35 & 0.70 \\
\hline $\mathrm{N}$ retention (g/pig) & 0.41 & -0.86 & 0.17 & 0.94 \\
\hline N excretion (g/pig) & 0.93 & 0.22 & 0.08 & 0.92 \\
\hline CP intake $(g / d)$ & 0.94 & -0.18 & 0.13 & 0.93 \\
\hline Lys intake $(\mathrm{g} / \mathrm{d})$ & 0.86 & -0.26 & -0.18 & 0.83 \\
\hline Urea plasma & 0.72 & 0.06 & -0.07 & 0.52 \\
\hline Protein plasma & 0.47 & -0.07 & -0.12 & 0.24 \\
\hline Variance $^{3}$ & 4.54 & 2.56 & 1.67 & 8.77 \\
\hline Proportion 4 & 0.38 & 0.21 & 0.14 & 0.73 \\
\hline
\end{tabular}


${ }^{1}$ Loadings were assumed to be significant above 0.7 .

${ }^{2}$ Calculated by summing the absolute values of the areas of the deviation between the regression line of the relative cumulative feed intake over a week and the step function of the observed cumulative feed intake. The regression line represents the hypothetical situation of a pig that eats the same amount of feed continuously over a week.

${ }^{3}$ Variability (eigenvalue) in data explained by each factor.

${ }^{4}$ Proportion of the total observed variation in data explained by each factor.

Despite the reported effect of meal frequency on AA metabolism, our analysis showed that plasmatic protein and plasmatic urea concentration were not related to feeding behaviour. The factor analysis in dataset 2 used in the present study, did not find any strong loadings for IIFI with the same factors retained by plasmatic protein and plasmatic urea concentration. Most studies that evaluate meal frequency use individually housed pigs and control feeding time, comparing a large range of meal frequency (from 2 to 12 meals per day). With those experimental protocols, feeding behavior is mainly described by meal frequency. By contrast, in our study pigs were housed together in a group and had free access to feed. In pigs with free access to feed, meal frequency is only one of the components of natural feeding behavior and between-animal variation is not as extreme as in studies using the conventional protocol. It has been shown that the number of meals that some pigs take can vary widely from day to day, resulting in irregular feeding behavior, even if these pigs have in average many daily meals (Salgado et al., 2021). Thus, when meal frequency is not controlled, its effect on protein metabolism may be decreased owing to interaction with the other components of feeding behavior. Additionally, only less frequent meal frequency might increase AA utilization for protein metabolism, while in ad libitum programs may not have the same effect (26). All this together might explain the small contribution of feeding behavior in body composition in ad libitum pigs as found and previously discussed in dataset 1 . Moreover, pigs from studies in which low meal frequency resulted in increased insulin concentrations with positive effects in protein metabolism $(4,5)$ were younger (final BW $52.8 \pm 0.8 \mathrm{~kg}$ and $92.6 \pm 1.1 \mathrm{~kg}$ ) than pigs from our study (final BW $135.3 \pm 8.3 \mathrm{~kg}, 116.8 \pm 8.2 \mathrm{~kg}$ and $116.7 \pm 6.7 \mathrm{~kg}$ for datasets 1,2 and 3 , respectively). This might also explain part of the lack of association of plasmatic protein and plasmatic urea concentration with feeding behaviour as the anabolic effect of insulin in protein synthesis decreases with age (23).

Table 5 Exploratory factor analysis ${ }^{1}$ (quartimax rotation) with correlation coefficients for growth performance, body composition, feeding behaviour and nutrient balance of finishing pigs in dataset 3 . 


\begin{tabular}{|c|c|c|c|c|c|c|}
\hline \multirow[t]{3}{*}{ Variable } & Factor1 & Factor2 & Factor3 & Factor4 & Factor5 & \multirow[t]{3}{*}{ Communality } \\
\hline & Fibre & $\mathrm{CP}$ & Protein & Feeding & Lipid & \\
\hline & Intake & intake & deposition & behaviour & deposition & \\
\hline $\begin{array}{l}\text { Number of daily } \\
\text { meals }\end{array}$ & 0.13 & -0.13 & 0.08 & 0.91 & 0.10 & 0.89 \\
\hline $\begin{array}{l}\text { Index of irregularity } \\
\text { of feed intake }\end{array}$ & -0.06 & 0.54 & 0.03 & -0.68 & 0.00 & 0.75 \\
\hline Body weight (kg) & 0.07 & -0.15 & 0.45 & -0.14 & 0.78 & 0.86 \\
\hline Feed-to-gain ratio & -0.09 & -0.75 & -0.47 & 0.15 & -0.07 & 0.81 \\
\hline $\begin{array}{l}\text { Protein deposition } \\
(\mathrm{g} / \mathrm{d})\end{array}$ & -0.12 & 0.03 & 0.97 & 0.05 & 0.03 & 0.96 \\
\hline $\begin{array}{l}\text { Lipid deposition } \\
(\mathrm{g} / \mathrm{d})\end{array}$ & 0.16 & -0.14 & -0.15 & 0.23 & 0.89 & 0.91 \\
\hline $\mathrm{N}$ retention (g/pig) & -0.12 & 0.03 & 0.97 & 0.05 & 0.03 & 0.96 \\
\hline N excretion (g/pig) & 0.47 & -0.82 & -0.12 & 0.15 & 0.18 & 0.97 \\
\hline $\mathrm{CP}$ intake $(\mathrm{g} / \mathrm{d})$ & 0.44 & -0.82 & 0.19 & 0.17 & 0.19 & 0.96 \\
\hline NDF intake (g/d) & 0.98 & -0.16 & -0.07 & 0.04 & 0.05 & 0.99 \\
\hline ADF intake $(\mathrm{g} / \mathrm{d})$ & 0.81 & -0.10 & -0.14 & -0.07 & 0.08 & 0.70 \\
\hline $\begin{array}{l}\text { NSP soluble intake } \\
(\mathrm{g} / \mathrm{d})\end{array}$ & 0.85 & -0.20 & -0.05 & 0.21 & -0.02 & 0.81 \\
\hline $\begin{array}{l}\text { NSP insoluble intake } \\
(\mathrm{g} / \mathrm{d})\end{array}$ & 0.47 & -0.60 & 0.30 & -0.07 & 0.11 & 0.69 \\
\hline Variance $^{3}$ & 3.05 & 2.69 & 2.50 & 1.51 & 1.50 & 11.25 \\
\hline Proportion 4 & 0.24 & 0.21 & 0.19 & 0.12 & 0.12 & 0.87 \\
\hline
\end{tabular}

${ }^{1}$ Loadings were assumed to be significant above 0.7 .

${ }^{2}$ Calculated by summing the absolute values of the areas of the deviations between the regression line of the relative cumulative feed intake over a week and the step function of the observed cumulative feed intake. The regression line represents the hypothetical situation of a pig that eats the same amount of feed continuously over a week.

${ }^{3}$ Variability (eigenvalue) in data explained by each factor.

${ }^{4}$ Proportion of the total observed variation in data explained by each factor 


\section{Conclusions}

The results of this study show that feeding behaviour as quantified by IIFI had no relevant relationship with the composition of body gain and pig performance. In cases where relationships were significant, the contribution of IIFI to the total variation in composition of the gain was no more than $12 \%$. The management of nutritional factors other than feeding behaviour might be explored to control nutrient utilization and body composition in finishing pigs. The validity of these conclusions is supported by fact that IIFI integrates most of the information on feeding behavior into a single measurement and considers intra-animal variation over a period of days.

\section{Abbreviations}

3P: 3-phase group feeding system; ADFl: Average daily feed intake; ADG: Average daily gain; BW: Body weight; CP: Crude protein; DXA: Dual-energy X-ray Absorptiometry; F:G: Feed-to Gain ratio; Fl: Feed intake; IIFI: Index of irregularity of feed intake; LdDG: Proportion of lipids in body weight gain; LP: Lipid deposition; Lys: Lysine; MPG: Multiphase group feeding system; MPI 100 Multiphase individual feeding system with $100 \%$ of lysine; MPI 110: Multiphase individual feeding system with $110 \%$ of lysine; MPI 80 : Multiphase individual feeding system with $80 \%$ of lysine; MPI 90: Multiphase individual feeding system with $90 \%$ of lysine; MPI: Multiphase individual feeding system; PD: Protein deposition; PdDG: Proportion of protein in body weight gain.

\section{Declarations}

\section{Ethics approval and consent to participate}

The animals were cared for according to a recommended code of practice (Canada, 2012) and the guidelines of the Canadian Council on Animal Care (CCAC, 2009). The animal trial was approved by the Ethical and Animal Welfare Committee of the Sherbrooke Research and Development Centre, Agriculture and Agri-Food Canada (Sherbrooke, QC, Canada).

\section{Consent for publication}

Not applicable.

\section{Availability of data and materials}

The datasets generated and/or analyzed during the current study belong to Her Majesty the Queen in Right of Canada, as represented by the Minister of Agriculture and Agri-Food Canada, and are not publicly available. Data can be obtained from the authors upon reasonable request and with the permission of the representative of Her Majesty the Queen in Right of Canada. 


\section{Competing interests}

There is no conflict of interest.

\section{Founding}

Financial support received from Agriculture and Agri-Food Canada.

\section{Authors' contributions}

Hector Salgado: Conceptualization, Methodology, Writing-Original draft, Formal Analysis Steve Méthot: Formal Analysis, Data Curation, Software, Writing-Review \& Editing Aline Remus: Writing-Review \& Editing Marie-Pierre Letoumeau-Montminy: Writing-Review \& Editing Candido Pomar: Supervision, Conceptualization, Writing-Review \& Editing.

\section{Acknowledgments}

The authors thank Dra Ines Andretta from the department of Animal Science, Universidade Federal do Rio Grande do Sul, Porto Alegre, RS, 91540-000, Brazil for assisting in the preparation of the data used in this study. This study was conducted as part of the first author's ongoing PhD thesis.

\section{References}

1. Arkfeld EK, Mohrhauser DA, King DA, Wheeler TL, Dilger AC, Shackelford SD, et al. Characterization of variability in pork carcass composition and primal quality1,2,3. Journal of animal science. 2017;95(2):697-708.

2. Carcò G, Gallo L, Dalla Bona M, Latorre MA, Fondevila M, Schiavon S. The influence of feeding behaviour on growth performance, carcass and meat characteristics of growing pigs. PloS one. 2018;13(10):e0205572.

3. Nielsen BL. On the interpretation of feeding behaviour measures and the use of feeding rate as an indicator of social constraint. Appl Anim Behav Sci. 1999;63(1):79-91.

4. Le Naou T, Floc'h L, Louveau I, Van Milgen J, Gondret F. Meal frequency changes the basal and timecourse profiles of plasma nutrient concentrations and affects feed efficiency in young growing pigs. Journal of animal science. 2014;92(5):2008-16.

5. Newman RE, Downing JA, Thomson PC, Collins CL, Henman DJ, Wilkinson SJ. Insulin secretion, body composition and pig performance are altered by feeding pattern. Animal Production Science. 2014;54(3):319-28. 
6. Schneider JD, Tokach MD, Goodband RD, Nelssen JL, Dritz SS, Derouchey JM, et al. Effects of restricted feed intake on finishing pigs weighing between 68 and 114 kilograms fed twice or 6 times daily. Journal of animal science. 2011;89(10):3326-33.

7. Andretta I, Pomar C, Kipper M, Hauschild L, Rivest J. Feeding behavior of growing-finishing pigs reared under precision feeding strategies. Journal of animal science. 2016;94(7):3042-50.

8. Labroue F, Guéblez R, Meunier-Salauen M-C, Sellier P. Alimentation électronique dans les stations publiques de contrôle des performances: paramètres descriptifs du comportement alimentaire. Journées de la recherche porcine en France. 1993;25:69-.

9. Salgado HH, Méthot S, Remus A, Létourneau-Montminy MP, Pomar C. A novel feeding behavior index integrating several components of the feeding behavior of finishing pigs. Animal. 2021;In press.

10. Andretta I, Pomar C, Rivest J, Pomar J, Lovatto PA, Radünz Neto J. The impact of feeding growingfinishing pigs with daily tailored diets using precision feeding techniques on animal performance, nutrient utilization, and body and carcass composition1. Journal of animal science. 2014;92(9):3925-36.

11. Andretta I, Pomar C, Rivest J, Pomar J, Radünz J. Precision feeding can significantly reduce lysine intake and nitrogen excretion without compromising the performance of growing pigs. animal. 2016;10(7):1137-47.

12. Dickner-Ouellet L. Optimisation de l'usage des coproduits dans l'alimentation des porcs en croissance: impact du type de fibre et de la xylanase sur la digestion des nutriments. 2018.

13. Pomar J, López V, Pomar C. Agent-based simulation framework for virtual prototyping of advanced livestock precision feeding systems. Comput Electron Agric. 2011;78(1):88-97.

14. Pomar C, Rivest J, editors. The effect of body position and data analysis on the estimation of body composition of pigs by dual energy X-ray absorptiometry (DEXA). Proceedings of the 46th Annual Conference of the Canadian Society of Animal Science, Lethbridge, AB, Canada; 1996.

15. Young J, Cai W, Dekkers J. Effect of selection for residual feed intake on feeding behavior and daily feed intake patterns in Yorkshire swine. Journal of animal science. 2011;89(3):639-47.

16. Colpoys JD, Johnson AK, Gabler NK. Daily feeding regimen impacts pig growth and behavior. Physiol Behav. 2016;159:27-32.

17. De Haer L, Luiting P, Aarts $H$. Relations among individual (residual) feed intake, growth performance and feed intake pattern of growing pigs in group housing. Livestock Production Science. 1993;36(3):233-53.

18. Labroue F, Guéblez R, Sellier P. Genetic parameters of feeding behaviour and performance traits in group-housed Large White and French Landrace growing pigs. Genetics selection evolution. 1997;29(4):451.

19. Tolkamp B, Schweitzer D, Kyriazakis IJJoDS. The biologically relevant unit for the analysis of shortterm feeding behavior of dairy cows. 2000;83(9):2057-68.

20. Patience JF, Rossoni-Serão MC, Gutiérrez NA. A review of feed efficiency in swine: biology and application. J Anim Sci Biotechnol. 2015;6(1):33. 
21. Möhn S, Fuller MF, Ball RO, de Lange CFM. Feeding Frequency and Type of Isotope Tracer Do Not Affect Direct Estimates of Lysine Oxidation in Growing Pigs. The Journal of Nutrition. 2003;133(11):3504-8.

22. Remus A, Hauschild L, Létourneau-Montminy M-P, Andretta I, Pomar C. Feeding behavior of growing and finishing pigs fed different dietary threonine levels in a group-phase feeding and individual precision feeding system. Translational Animal Science. 2020;4(4):txaa177.

23. Davis $T$, Suryawan $A$, Orellana R, Fiorotto $M$, Burrin D. Amino acids and insulin are regulators of muscle protein synthesis in neonatal pigs. Animal. 2010;4(11):1790-6.

24. Liu J, Liu Z, Chen L, Zhang H. iTRAQ-based proteomic analysis reveals alterations in the liver induced by restricted meal frequency in a pig model. Nutrition. 2016;32(7-8):871-6.

25. Yan H, Cao S, Li Y, Zhang H, Liu J. Reduced meal frequency alleviates high-fat diet-induced lipid accumulation and inflammation in adipose tissue of pigs under the circumstance of fixed feed allowance. European journal of nutrition. 2019:1-14.

26. Silva WCd, Campos PHRF, Santos LSd, Veira AM, Fraga AZ, Hauschild L. Sequential feeding with diets varying in amino acid content for growing-finishing pigs. Scientia Agricola. 2021;78(4).

\section{Figures}




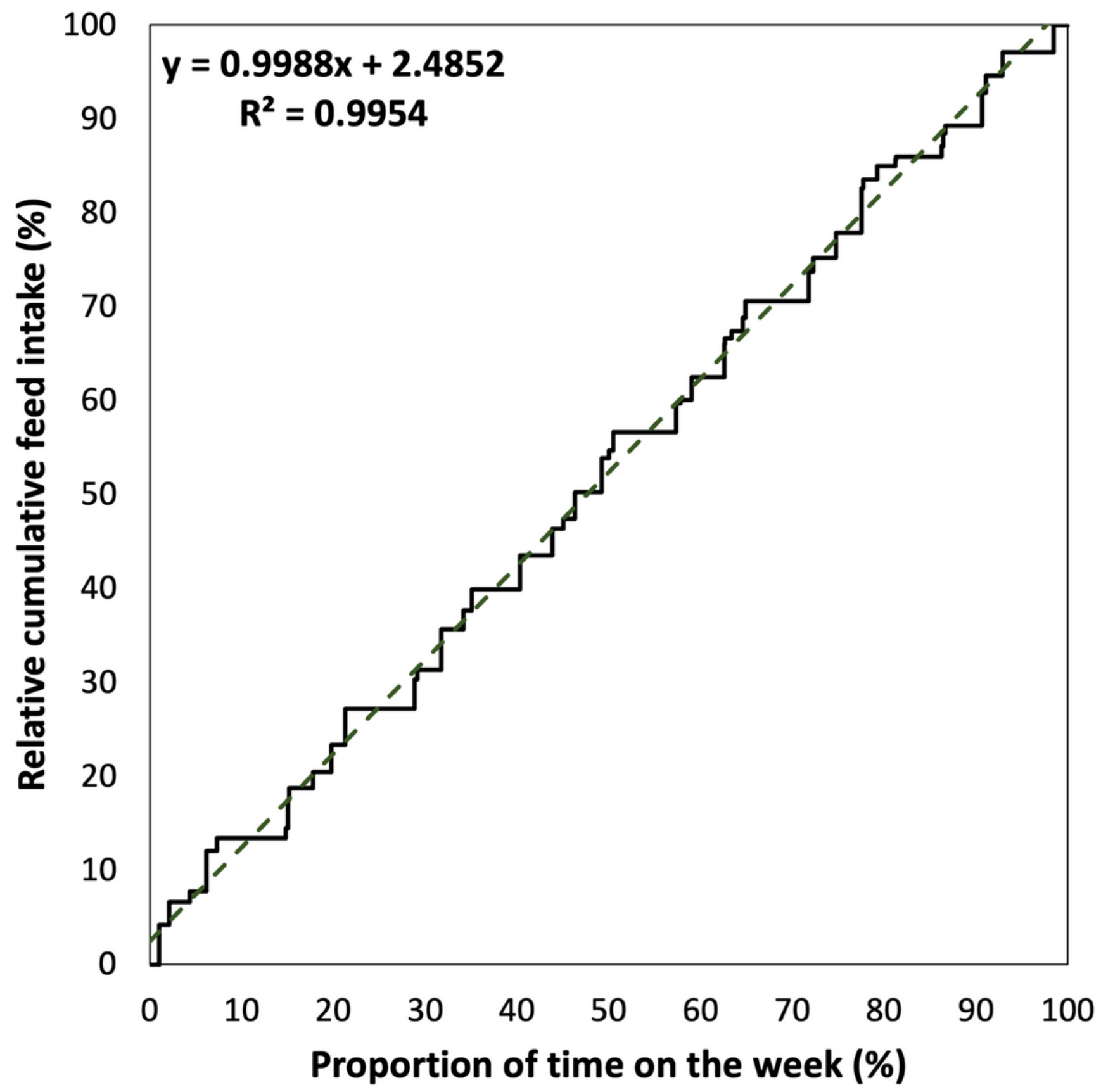

—Step function of observed RCFI _ - - Regression line

Figure 1

Weekly relative cumulative feed intake over relative time of a typical pig. The regression line (green dotted line) represents a hypothetical situation where a pig would continually eat the same amount of feed over time, while the step function (black solid line) plots the increases of relative cumulative feed intake (RCFI) over the relative time. For some pigs, the regression line does not start at the origin $(0,0)$ and does not finish at the end point $(100,100)$. 
Dataset 1

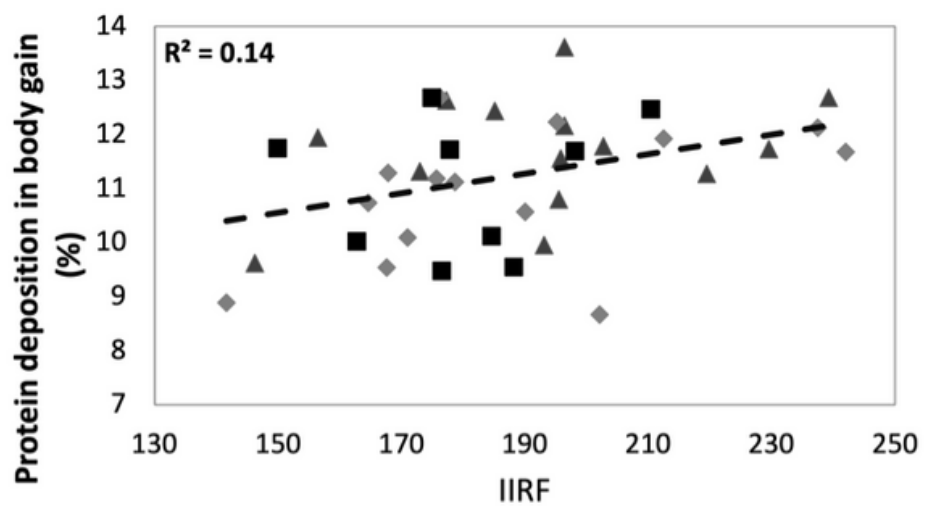

$\triangle 3 P \diamond M P G \square M P I$
Dataset 2

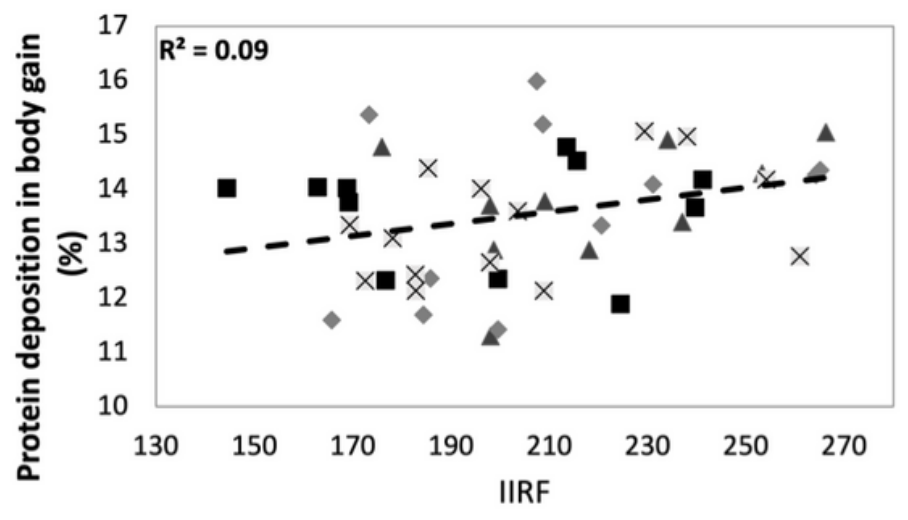

$\triangle 3 P \diamond \mathrm{MPI} 110 \quad \mathrm{MPI} 100 \times \mathrm{MPI} 90$

\section{Figure 2}

Linear relationship between the index of irregularity of feed intake (IIFI) and body gain leaness (\%) in datasets 1 and $2(P<0.05)$. The treatment effect (3P, MPG, MPI, MPI 110-100-90) and the interaction treatment $\times$ IIFI were not significant for both datasets $(P>0.05)$. The index of irregularity of feed intake was calculated by summing the values of the areas of the deviations between the regression line of the relative cumulative feed intake over a week and the step function of the observed cumulative feed intake. The regression line used to estimate the IIFI represents the hypothetical situation of a pig that eats the same amount of feed continuously over a week.

\section{Supplementary Files}

This is a list of supplementary files associated with this preprint. Click to download.

- Supplementarymaterial97.docx 